\title{
Measurement of osteogenic exercise - how to interpret accelerometric data?
}

\author{
Timo Jämsä ${ }^{1,2}{ }^{*}$, Rïkka Ahola ${ }^{1}$ and Raija Korpelainen ${ }^{1,3,4,5}$ \\ ${ }^{1}$ Department of Medical Technology, Institute of Biomedicine, University of Oulu, Oulu, Finland \\ ${ }^{2}$ Department of Diagnostic Radiology, Oulu University Hospital, Oulu, Finland \\ ${ }^{3}$ Department of Sports and Exercise Medicine, Oulu Deaconess Institute, Oulu, Finland \\ ${ }^{4}$ Unit of General Practice, Institute of Health Sciences, University of Oulu, Oulu, Finland \\ ${ }^{5}$ Unit of General Practice, Institute of Health Sciences, University Hospital of Oulu, Oulu, Finland
}

\section{Edited by:}

Heikki Olavi Tikkanen, University of

Helsinki, Finland

Reviewed by:

Saija Kontulainen, University of

Saskatchewan, Canada

Thorsten Rudroff, University of

Colorado at Boulder, USA

*Correspondence:

Timo Jämsä, Department of Medical Technology, University of Oulu, P.O.

Box 5000, 90014 Oulu, Finland.

e-mail: timo.jamsa@oulu.fi
Bone tissue adapts to its mechanical loading environment. We review here the accelerometric measurements with special emphasis on osteogenic exercise. The accelerometric method offers a unique opportunity to assess the intensity of mechanical loadings. We present methods to interpret accelerometric data, reducing it to the daily distributions of magnitude, slope, area, and energy of signal. These features represent the intensity level of physical activities, and were associated with the changes in bone density, bone geometry, physical performance, and metabolism in healthy premenopausal women. Bone adaptations presented a dose- and intensity dependent relationship with impact loading. Changes in hip were threshold dependent, indicating the importance of high-impacts exceeding acceleration of $4 \mathrm{~g}$ or slope of $100 \mathrm{~g} / \mathrm{s}$ as an osteogenic stimulus. The number of impacts needed was 60/day. We also present the daily impact score to describe the osteogenic potential of daily mechanical loading with a single score. The methodology presented here can be used to study musculoskeletal adaptation to exercise in other target groups as well.

Keywords: physical activity, exercise, accelerometer, bone, osteoporosis, BMD, mechanical loading, biomechanics

\section{BACKGROUND}

Bone is dynamic tissue that is able to adapt its structure and strength to mechanical loading environment. Aging and related changes in hormones, nutrition, muscle mass, and other factors disturb this adaptation process, making bones weaker and fragile (Seeman and Delmas, 2006). Due to aging population, osteoporosis and fragility fractures have become a major public health concern worldwide. Thus, it is necessary to find efficient preventive strategies.

Physical exercise as a non-pharmaceutical tool has been extensively studied in preventing bone loss. It is well known that mechanical loading increases and maintains bone mass and strength. Exercises including high-impact loading have been shown to be beneficial for bones, and high-impact activities are most effective in improving femoral neck bone mineral density (BMD) at the hip (Wolff et al., 1999; Wallace and Cumming, 2000), a common site of osteoporotic fracture. However, the dose-response, i.e., the optimal amount, intensity, frequency, and duration of bone exercise, is far less known, because of technological challenges for long-term evaluation of the osteogenic features of exercise in population-based studies. Accelerometerbased measurement of body movement is an accepted method for monitoring physical activity (Mathie et al., 2004; Chen and Bassett, 2005). The method can also be used to assess the mechanical loading of bones, and thus for optimizing exercises to prevent osteoporosis.

Here we review the accelerometric measurement of motion with special emphasis on osteogenic exercise, and the findings obtained during our set of studies revealing dose-response and the determinants of physical activity and exercise beneficial for the bone.

\section{ACCELEROMETRIC MEASUREMENT OF HUMAN MOTION}

Accelerometer sensors measure acceleration, i.e., the change in speed with respect to time, expressed as $\left(\mathrm{m} / \mathrm{s}^{2}\right)$ or multiplies of the acceleration of gravity $\left(g=9.81 \mathrm{~m} / \mathrm{s}^{2}\right)$. It is to be noted that accelerometers do not measure static motion. The derivative of acceleration with respect to time is jerk $\left(\mathrm{m} / \mathrm{s}^{3}\right)$ or $(\mathrm{g} / \mathrm{s})$.

Accelerometers measure the acceleration in one to three orthogonal dimensions (e.g., vertical, anterior-posterior, and mediallateral planes of human). The measured total acceleration involves both acceleration due to movement and acceleration due to gravity. Accelerometers have become a valuable method of assessing human motion in clinical research and everyday life (Mathie et al., 2004; Plasqui and Westerterp, 2007). They are small, unobtrusive, and light-weight, and they are also able to record inactivity.

The magnitude of acceleration in human movements depends on the measurement site and the activity that is being done. The highest vertical values of up to $15 \mathrm{~g}$ or even more are measured close to the site of ground contact (Bhattacharya et al., 1980; Gross and Nelson, 1988; Moran and Marshall, 2006). The signal is attenuated greatly as the shock wave propagates up the body, and attenuation is present even in the ankle joint (Gross and Nelson, 1988). Impact energy is absorbed by the whole locomotion system: the muscles, bone, ligaments, and tendons. 
The place of attachment of the accelerometer on the human body is of great importance. If the whole body is being studied, waist or back give an estimate of the acceleration at the center of mass. Sensors attached to the wrist, arm, or ankle provide information on the movement of the extremities. Regarding sensor attachment, subject compliance to wearing the sensor is crucial in long-term conditions (Mathie et al., 2004; Trost et al., 2005).

Raw acceleration data can be described with basic statistics, such as mean, root-mean-square (RMS) value, or variance (Godfrey et al., 2008), but a common way to express physical activity is to use counts. Counts are arbitrary and not universal, since they depend on signal processing (Chen and Bassett, 2005) and also on sensor properties. Counts can be determined for example as (1) the number of times the acceleration signal exceeds a pre-defined threshold, (2) the maximum acceleration value during the time period (epoch), or (3) the integral of the signal for the epoch (Mathie et al., 2004; Chen and Bassett, 2005). Several other signal analysis tools can also be applied, such as pattern recognition, wavelets, classification trees, or neural networks (Godfrey et al., 2008). Standardized procedures to calculate physical activity from the raw acceleration data are called for (Ward et al., 2005; Kavanagh and Menz, 2008). Based on specific cut point values for counts per minute, physical activity is described as minutes spent in different exercise intensities (vigorous, moderate, light, or sedentary; Freedson et al., 1998; Janz et al., 2004). Counts per minute can also be calibrated to energy expenditure, i.e., metabolic energy equivalents (MET; Trost et al., 2005; Plasqui and Westerterp, 2007). The interpretation of count data depends on cut-points and prediction equations used (Ward et al., 2005).

\section{MEASUREMENT OF OSTEOGENIC EXERCISE}

Despite of vast literature on the use of accelerometers in measuring physical activity, studies using accelerometers to determine optimal exercise for the bone are few. In terms of bone loading, activity counts or MET levels do not directly provide information on mechanical loading or strain levels. Bone can adjust to a short bout of mechanical loading, and a load of high strain with only a few repetitions may optimize the osteogenic response (Turner, 1998; Kato et al., 2006). A surrogate measure of bone loading can be obtained with accelerometers.

For a bone undergoing an impact with the ground, the acceleration $a$ is related to the external force $F$ according to the effective mass $m$ involved $(F=m a)$. Furthermore, stress $\sigma$ is the force applied to the cross-sectional area $A$ and strain $\varepsilon$ is the stress divided by the elastic modulus $E$. It follows that

$\varepsilon=\frac{m a}{A E}$.

Thus, there is an association between acceleration $a$ and strain $\varepsilon$. Consequently, strain rate is related to the rate of acceleration change (jerk).

An accelerometer-based bone exercise recorder has been developed in our research group (Vihriälä et al., 2003, 2004; Jämsä et al., 2005, 2006). It is worn at the waist, close to the hip, and it measures vertical acceleration peaks caused by impacts. The distribution of daily impacts according to acceleration levels is recorded, which enables analysis of the number of loadings, and also the various features of the activities in terms of magnitude, slope (jerk), area, and energy of the acceleration signal.

A combined parameter to describe the total effect of daily impact activity would be valuable. Previously, daily stress stimulus (Carter et al., 1987) and osteogenic index (Turner, 1998) theories were suggested to describe the osteogenic potential of exercise. These theories consider exponential or logarithmic relationships between loading numbers and magnitude. Inspired by these theories, we developed and tested the daily impact score (DIS) to describe the overall daily exercise using a single score (Ahola et al., 2010). DIS was calculated from the daily distributions of accelerations in two ways, using exponential (DIS $\mathrm{Exp}_{\text {) }}$ or logarithmic $\left(\right.$ DIS $\left._{\text {Log }}\right)$ relationship between acceleration magnitude and number of loading cycles:

$\mathrm{DIS}_{\mathrm{Exp}}=\left(\sum_{j=1}^{32} N_{j} a_{j}^{m}\right)^{1 / m}$

and

$\mathrm{DIS}_{\text {Log }}=\sum_{j=1}^{32} a_{j} \ln \left(N_{j}+1\right)$

in which $a_{j}$ is the $j$ th acceleration level of impacts and $N_{j}$ is the daily number of impacts at the $j$ th level. Exponent $m$ is a weighting factor for the relative importance of the magnitude.

\section{LONG-TERM ACCELERATION DATA FROM AN EXERCISE INTERVENTION STUDY}

Acceleration data were obtained from a 12-month populationbased randomized controlled exercise intervention (Vainionpää et al., 2005, 2006) in healthy women (35-40 years, $N=34$ in the high-impact exercise group and $N=30$ in the control group). Average (SD) height was 162.9 (SD 6.0) $\mathrm{cm}$ and BMI was 25.5 (4.6) $\mathrm{kg} / \mathrm{m}^{2}$. Originally, the study sample was chosen to represent a clinically potential target group for early prevention of osteoporosis. The individual daily bone loading was assessed with the waist-worn bone exercise recorder (Newtest Ltd., Oulu, Finland). The subjects were asked to carry the black-box recorder close to their right iliac crest daily during all waking hours. The continuous recording time was several weeks.

The daily numbers of vertical impacts were recorded in 32 acceleration levels from 0.3 to $9.9 \mathrm{~g}$ (acceleration of gravity subtracted, i.e., $0 \mathrm{~g}$ equal to standing). The distribution of average daily number of impacts with different magnitudes, slopes (jerk), areas, and signal energies was analyzed. Figure 1 shows the distribution of average daily number of impacts at different acceleration levels in the high-impact exercise group and controls. The average DIS $S_{\operatorname{Exp}}$ and DIS $_{\text {Log }}$ were also calculated.

Exercise-induced bone changes during the 12-month study were analyzed with respect to the acceleration data. BMD was measured at the proximal femur and lumbar spine with dual Xray absorptiometry (Hologic Delphi QDR, Bedford, MA, USA), and cross-sectional geometry of mid-femur was assessed with spiral computed tomography (Siemens Somatom Emotion, Munich, 


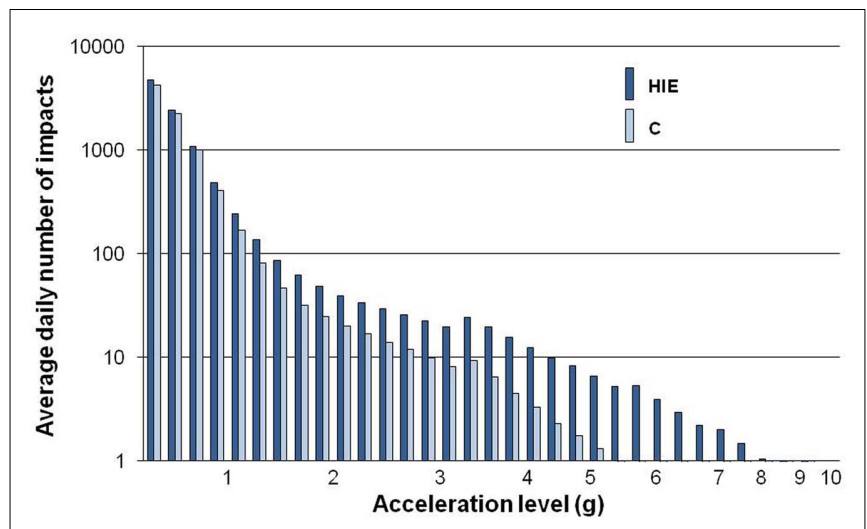

FIGURE 1 |The average daily distribution of impacts during the 12-month high-impact exercise intervention in premenopausal women. $\mathrm{HIE}$, high-impact exercise group $(N=34)$; $\mathrm{C}$, control group $(N=30)$. Modified from Jämsä et al. (2006).

Germany). Calcaneal ultrasound attenuation and velocity were assessed with quantitative ultrasound (Hologic Sahara, Bedford, MA, USA). High-impact training effects on bone metabolism, physical performance, and risk factors of cardiovascular diseases were also evaluated.

\section{FINDINGS}

Our study demonstrated that 12 months of regular impact exercise favored bone formation, increased BMD in weight-bearing bones, especially at the hip, and led to geometric adaptations by increasing periosteal circumference of the femur (Vainionpää et al., 2005, 2006, 2007a). Bone adaptations had a dose- and intensity dependent relationship with measured impact loading. The number of high-impacts needed to achieve this stimulation was 60/day (Vainionpää et al., 2006). Impact exercise also had a favorable effect on bone metabolism, physical performance, and cardiorespiratory risk factors by increasing maximal oxygen uptake, dynamic leg strength, and decreasing serum basal parathormone levels, low-density lipoproteins, and waist circumference (Vainionpää et al., 2007b, 2009). These changes were dose-dependent at wide intensity range.

The magnitude, slope, area, and energy of the acceleration signal were all significant determinants of BMD changes (Vainionpää et al., 2006; Heikkinen et al., 2007). Changes in proximal femur were threshold dependent, indicating the importance of highimpacts exceeding acceleration of $4 \mathrm{~g}$ as an osteogenic stimulus, whereas the threshold of acceleration slope for improving BMD at the hip was $100 \mathrm{~g} / \mathrm{s}$. Similarly, acceleration peak area of $2 \mathrm{~m} / \mathrm{s}$, and signal energy of $75 \mathrm{~m}^{2} / \mathrm{s}^{3}$ were found to be thresholds for BMD changes at the hip. These high intensity impacts can be achieved during exercise including fast movements such as running and jumping. The study also showed that even lower intensity exercise

\section{REFERENCES}

Ahola, R., Korpelainen, R., Vainionpää, A., and Jämsä, T. (2010). Daily impact score in long-term acceleration measurements of high-impact exercise. J. Biomech. 43, 1960-1964.
Bhattacharya, A., McCutcheon, E. P., Shvartz, E., and Greenleaf, J. E. (1980). Body acceleration distribution and $\mathrm{O} 2$ uptake in humans during running and jumping. J. Appl. Physiol. 49, 881-887.

at levels above $1 \mathrm{~g}$ was osteogenic, the number of impacts being the most significant predictor of change in bone circumference (Vainionpää et al., 2007a).

Daily impact score calculated in either of the ways was significantly higher in the exercise group than in the control group (Ahola et al., 2010). DIS Exp $_{\text {and DIS }}$ Log were strongly correlated $(R=0.98)$, and were significantly associated with 12-month BMD changes at the hip and geometry changes at the mid-femur in the exercising women.

\section{CONCLUSION}

Accelerometric measurement of body movement is a valuable tool for objective assessment of physical activity. Since bone adapts to mechanical loadings, the accelerometric method offers a unique opportunity to assess the intensity of exercise-related impact loadings. We presented a method to interpret accelerometric data, reducing it to the daily distributions of the magnitude, slope, area, and energy of the acceleration signal. All these features appeared to represent the intensity level of physical activities, and were associated with the changes in bone density, bone geometry, physical performance, and metabolism. Bone adaptations presented a dose- and intensity dependent relationship with measured impact loading. Changes in proximal femur were threshold dependent, indicating the importance of high-impacts exceeding acceleration of $4 \mathrm{~g}$ or acceleration slope of $100 \mathrm{~g} / \mathrm{s}$ as an osteogenic stimulus. The number of impacts needed to achieve this stimulation was 60/day.

We also presented the DIS to describe the osteogenic potential of daily mechanical loading with a single score. DIS offers a method for describing the individual daily osteogenic loading with a single score in healthy premenopausal women.

There are challenges related to accelerometer compliance, data reduction, and data interpretation in long-term measurements. In the set of studies presented here, the impacts were measured on a daily basis and we were not able to distinguish single exercise or rest periods. Furthermore, muscle pull of bone cannot be measured by accelerometers. Future studies should aim to integrate the different characteristics of loading into a single model to reveal which component of loading best predicts bone changes.

The results obtained using quantification of physical activity provide new information for designing optimal and feasible training programs that can prevent lower extremity and lumbar bone loss in healthy premenopausal women. The methodology presented here can be used to study bone adaptation to physical exercise in other age groups as well. It also offers a possibility to examine the dose-response of other tissues sensitive to mechanical loading, such as articular cartilage. Since the memory capacity of accelerometers has expanded rapidly, it is today possible to record several weeks of raw data without data reduction during data collection. The current approach can thus be extended to study the dose-response in further details, e.g., the restoration of mechanosensitivity during rest periods between bouts of impacts.

Carter, D. R., Fyhrie, D. P., and Whalen, R. T. (1987). Trabecular bone density and loading history: regulation of connective tissue biology by mechanical energy. J. Biomech. 20, 785-794.
Chen, K. Y., and Bassett, D. R. Jr. (2005). The technology of accelerometry-based activity monitors: current and future. Med. Sci. Sports Exerc. 37(Suppl.), S490-S500. 
Freedson, P. S., Melanson, E., and Sirard, J. (1998). Calibration of the computer science and applications, Inc. accelerometer. Med. Sci. Sports Exerc. 30, 777-781.

Godfrey, A., Conway, R., Meagher, D., and ÓLaighin, G. (2008). Direct measurement of human movement by accelerometry. Med. Eng. Phys. 30, 1364-1386.

Gross, T. S., and Nelson, R. C. (1988). The shock attenuation role of the ankle during landing from a vertical jump. Med. Sci. Sports Exerc. 20, 506-514.

Heikkinen, R., Vihriälä, E., Vainionpää, A., Korpelainen, R., and Jämsä, T. (2007). Acceleration slope of exercise-induced impacts is a determinant of changes in bone density. J. Biomech. 40, 2967-2974.

Jämsä, T., Vainionpää, A., Vihriälä, E., Korpelainen, R., and Leppäluoto, J. (2006). Effects of daily physical activity on proximal femur. Clin. Biomech. 21, 1-7.

Jämsä, T., Vainionpää, A., Vihriälä, E., Korpelainen, R., Rinta-Paavola, A., and Leppäluoto, J. (2005). Accelerometer-based long-term monitoring of physical exercise. IFMBE Proc. 11, 5.

Janz, K. F., Burns, T. L., Levy, S. M., Torner, J. C., Willing, M. C., Beck, T. J., Gilmore, J. M., and Marshall, T. A. (2004). Everyday activity predicts bone geometry in children: the Iowa bone development study. Med. Sci. Sports Exerc. 36, 1124-1131.

Kato, T., Terashima, T., Yamashita, T., Hatanaka, Y., Honda, A., and Umemura, Y. (2006). Effect of lowrepetition jump training on bone mineral density in young women. $J$. Appl. Physiol. 100, 839-843.

Kavanagh, J. J., and Menz, H. B. (2008). Accelerometry: a technique for quantifying movement patterns during walking. Gait Posture 28, 1-15.

Mathie, M. J., Coster, A. C., Lovell, N. H., and Celler, B. G. (2004). Accelerometry: providing an integrated, practical method for long-term, ambulatory monitoring of human movement. Physiol. Meas. 25, R1-R20.

Moran, K. A., and Marshall, B. M. (2006). Effect of fatigue on tibial impact accelerations and knee kinematics in drop jumps. Med. Sci. Sports Exerc. 38, 1836-1842.

Plasqui, G., and Westerterp, K. R. (2007). Physical activity assessment with accelerometers: an evaluation against doubly labeled water. Obesity 15, 2371-2379.

Seeman, E., and Delmas, P. D. (2006). Bone quality - the material and structural basis of bone strength and fragility. N. Engl. J. Med. 354, 2250-2261.

Trost, S. G., McIver, K. L., and Pate, R. R. (2005). Conducting accelerometerbased activity assessments in fieldbased research. Med. Sci. Sports Exerc. 37, S531-S543.

Turner, C. H. (1998). Three rules for bone adaptation to mechanical stimuli. Bone 23, 399-407.

Vainionpää, A., Korpelainen, R., Leppäluoto, J., and Jämsä, T. (2005). Effects of high-impact exercise on bone mineral density - a randomized controlled trial in premenopausal women. Osteoporos. Int. 16, 191-197.
Vainionpää, A., Korpelainen, R., Väänänen, K., Haapalahti, J., Jämsä, T., and Leppäluoto, J. (2009). Effect of exercise on bone metabolism. Osteoporos. Int. 20, 1725-1733.

Vainionpää, A., Korpelainen, R., Vihriälä, E., Rinta-Paavola, A., Leppäluoto, J., and Jämsä, T. (2006). Intensity of exercise is associated with bone density change in premenopausal women. Osteoporos. Int. 17, 455-463.

Vainionpää, A., Korpelainen, R. Vihriälä, E., Rinta-Paavola, A. Sievänen, H., Leppäluoto, J., and Jämsä, T. (2007a). Effect of impact exercise and its intensity on bone geometry in weight-bearing tibia and femur. Bone 40, 604-611.

Vainionpää, A., Korpelainen, R. Kaikkonen, H., Knip, M., Leppäluoto, J., and Jämsä, T. (2007b). Effect of impact exercise on physical performance and cardiovascular risk factors. Med. Sci. Sports Exerc. 39, 756-763.

Vihriälä, E., Oksa, J., Karkulehto, J., Korpelainen, R., Myllylä, R., and Jämsä, T. (2004). Reliability of an accelerometer for assessment of body movements. Technol. Health Care 12, 122-124.

Vihriälä, E., Saarimaa, R., Myllylä, R. and Jämsä, T. (2003). A device for long term monitoring of impact loading on the hip. Mol. Quantum Acoust. 24, 211-224.

Wallace, B. A., and Cumming, R. G. (2000). Systematic review of randomized trials of the effect of exercise on bone mass in pre- and postmenopausal women. Calcif. Tissue Int. 67, 10-18.
Ward, D. S., Evenson, K. R., Vaughn, A., Rodgers, A. B., and Troiano, R. P. (2005). Accelerometer use in physical activity: best practices and research recommendations. Med. Sci. Sports Exerc. 37, S582-S588.

Wolff, I., van Croonenborg, J. J., Kemper, H. C., Kostense, P. J., and Twisk, J. W. (1999). The effect of exercise training programs on bone mass: a meta-analysis of published controlled trials in pre- and postmenopausal women. Osteoporos. Int. 9, 1-12.

Conflict of Interest Statement: The authors declare that the research was conducted in the absence of any commercial or financial relationships that could be construed as a potential conflict of interest.

Received: 01 July 2011; paper pending published: 26 July 2011; accepted: 03 October 2011; published online: 18 October 2011.

Citation: Jämsä T, Ahola $R$ and Korpelainen $R$ (2011) Measurement of osteogenic exercise - how to interpret accelerometric data? Front. Physio. 2:73. doi: 10.3389/fphys.2011.00073

This article was submitted to Frontiers in Clinical and Translational Physiology, a specialty of Frontiers in Physiology. Copyright (C) 2011 Jämsä, Ahola and Korpelainen. This is an open-access article subject to a non-exclusive license between the authors and Frontiers Media $S A$, which permits use, distribution and reproduction in other forums, provided the original authors and source are credited and other Frontiers conditions are complied with. 